\title{
ИССЛЕДОВАНИЯ ОСОБЕННОСТЕЙ ВОЛНОВЫХ ПРОЦЕССОВ В ПОЛЯХ ДИНАМИЧЕСКИХ ХАРАКТЕРИСТИК ОТРАЖЕННЫХ СЕЙСМИЧЕСКИХ ВОЛН
}

\author{
И.И. СЕМЕРИКОВА \\ Горный институт УрО РАН, г. Пермь
}

\begin{abstract}
Аннотация. На практике при количественных определениях полной ясности и единых позиций в оценке разрешающей способности не существует. Нужно помнить, что каждое отражение является результатом сложной интерференции нескольких простых сигналов. Такие физические явления как «рассеяние» и «дифракция» зависят от соотношения размеров частицы и длины волны, которая падает на частицу. В случае, когда частица намного меньше длины волны, рассеяние является частным случаем рэлеевского рассеяния. В случае близости размеров частицы к длине волны диаграмма направленности рассеяния становится сложной. Проявляется интерференция волн, отражённых от различных участков поверхности частицы. В этом случае явление рассматривают с точки зрения теории рассеяния Ми. Если размеры сферы намного больше длины волны, то происходит преломление и отражение волн, которые описываются формулами Френеля. В данной работе демонстрируются результаты анализа спектральных характеристик сейсмических волн, связи их изменчивости с наличием структурных и скоростных неоднородностей. Выделяются области уменьшения энергии доминантной частоты при наличии скоростных неоднородностей. Выделяются области повышенной энергии высокочастотных составляющих спектра при наличии зоны мелких разноориентированных трещин. На разрезах амплитудного спектра выявлены локальные области уменьшения энергии высоких частот при наличии вертикальной горной выработки «ствол». Диаметр выработки меньше диаметра первой зоны Френеля в 17-22 раза и длины волны в 5-6 раз. Отклик этого объекта не наблюдается на временном разрезе, но наблюдается в спектральных характеристиках.

Ключевые слова: разрешающая способность сейсморазведки, дифракция, рассеивающие неоднородности, длина волны, зона Френеля.
\end{abstract}

\section{Введение}

Разрешающая способность является одной из фундаментальных характеристик любого метода исследований. Для сейсморазведки МОВ в классической формулировке этого понятия она зависит от двух параметров: длины волны изучаемых колебаний (по вертикали) и размера зоны Френеля (по латерали). Однако на практике при количественных определениях полной ясности и единых позиций в оценке разрешающей способности не существует $[1,2]$. В своей работе Кондратьев О. К. [1] отмечает, что при определении разрешающей способности в сейсморазведке МОВ необходимо отметить два момента. Первый - при использовании одного волнового поля разрешающая способность решения разных задач и даже одной задачи разными способами может быть не одинакова. Второй - разрешающая способность зависит от уровня помех в этом волновом поле, поскольку даже при отличном качестве материалов следует учитывать наличие погрешностей решения конкретной задачи, обусловленных отличием идеализированных моделей разреза и цифровых записей сейсмограмм от реальной среды и связанного с ней волнового поля. В связи с чем, реальной разрешающей способностью сейсморазведки следует считать способность решения конкретной задачи данным конкретным способом в данных конкретных условиях с некоторой заданной точностью [1].

В работе Спасского Б. А. [2] указывается, что основы современных представлений о разрешающей способности сейсморазведки МОВ заложены в работах И.С. Берзон, которая впервые четко сформулировала решение в рамках кинематических задач лучевого метода. Для случая слоистых сред ей принадлежит первое определение понятия разрешающей способности: "Разрешающая способность сейсморазведки при изучении 
слоистых сред характеризуется степенью детальности, с которой может быть произведено расчленение геологического разреза, она определяется как минимальное расстояние между двумя объектами (например, границами, соответствующими кровле и подошве пласта), на котором они еще различимы как два разных объекта, а не сливаются в один“. При оценке горизонтальной разрешенности считается, что горизонтальные неоднородности, размеры которых превышают величину диаметра первой зоны Френеля, могут быть обнаружены по кинематическим особенностям сейсмической записи, а при размерах неоднородностей менее диаметра первой зоны Френеля - лишь с помощью анализа динамических параметров. При этом разрешающая способность сейсморазведки по горизонтали зависит не только от скорости в покрывающей среде, частоты колебаний, глубины до целевой границы, но и от угла падения центрального луча на границу. На сейсмических разрезах изображается интегральная волновая картина, формирующаяся при распространении сейсмических волн в геологической среде, и взаимное расположение пластов горных пород - лишь один из многих факторов, определяющих эту картину. В процессе регистрации, анализа и обработки сейсмических данных подавляются множество сигналов, не связанные с реальными отражениями от границ пластов. При этом нужно помнить, что каждое отражение является результатом сложной интерференции нескольких (иногда нескольких десятков) простых сигналов.

Такие физические явления как «рассеяние» и «дифракция» зависят от соотношения размеров частицы и длины волны, которая падает на частицу. В случае, когда частица намного меньше длины волны, рассеяние является частным случаем рэлеевского рассеяния. Интенсивность рассеяния зависит от частоты в четвертой степени, что приводит к сильному рассеянию коротких волн. В случае близости размеров частицы к длине волны диаграмма направленности рассеяния становится сложной. Проявляется интерференция волн, отражённых от различных участков поверхности частицы. Интенсивность рассеянного под определенным углом света зависит от того, сколько раз волна укладывается на диаметре частицы, поэтому она сильно зависит от размеров частицы. В этом случае явление рассматривают с точки зрения «задачи (теории) Густова Ми» - рассеяние Ми. Если размеры сферы намного больше длины волны, то поверхность сферы будет вести себя как плоская поверхность. Происходит преломление и отражение волн, которые описываются формулами Френеля.

\section{Метод и результаты}

Подход для спектрального анализа по временным разрезам всех профилей заключался в расчете и анализе дифференциальных и интегральных амплитудно-частотных спектров. В качестве дифференциальных характеристик сейсмической записи рассчитаны потрассные спектры, суть которых состоит в расчете амплитудно-частотного спектра в узком временном окне, скользящем вдоль каждой трассы. Для изучения поведения интегральных характеристик рассчитаны суммарные спектры, суть которых - в расчете частотного спектра в широком временном окне, охватывающем крупный глубинный интервал пород, и по совокупности сейсмотрасс на протяженном латеральном участке, или даже на всем профиле. Сейсморазведочные исследования выполнены в Отделе активной сейсмоакустики «Горного института ГИ УрО РАН» по площадной сети профилей МОГТ на территории Верхнекамского месторождения калийных солей Усть-Яйвинский участок (рис.1).

Отражающие горизонты (рис. 3) на типичном временном разрезе соответствуют: кровле соляно-мергельной толщи - СМТ; кровле переходной пачки, т.е. первого сверху по разрезу пласту каменной соли - ПП; кровле мощного пласта карналлита - Ек в карналлитовой зоне; кровле сильвинитовой зоны - СИЛ; кровле тонкого пласта маркирующей глины, расположенного в кровле мощной (600 м) толщи подстилающей камен- 
ной соли, - МГ. Желтым цветом окрашены зоны нарушения регулярной волновой картины. Природа этих нарушений неоднозначна, они могут быть обусловлены целым радом факторов: структурным фактором; литологическим; тектоническим - пликативным и дизьюнктивным; техногенным - изменением напряженно-деформированного состояния в области горных выработок и др.

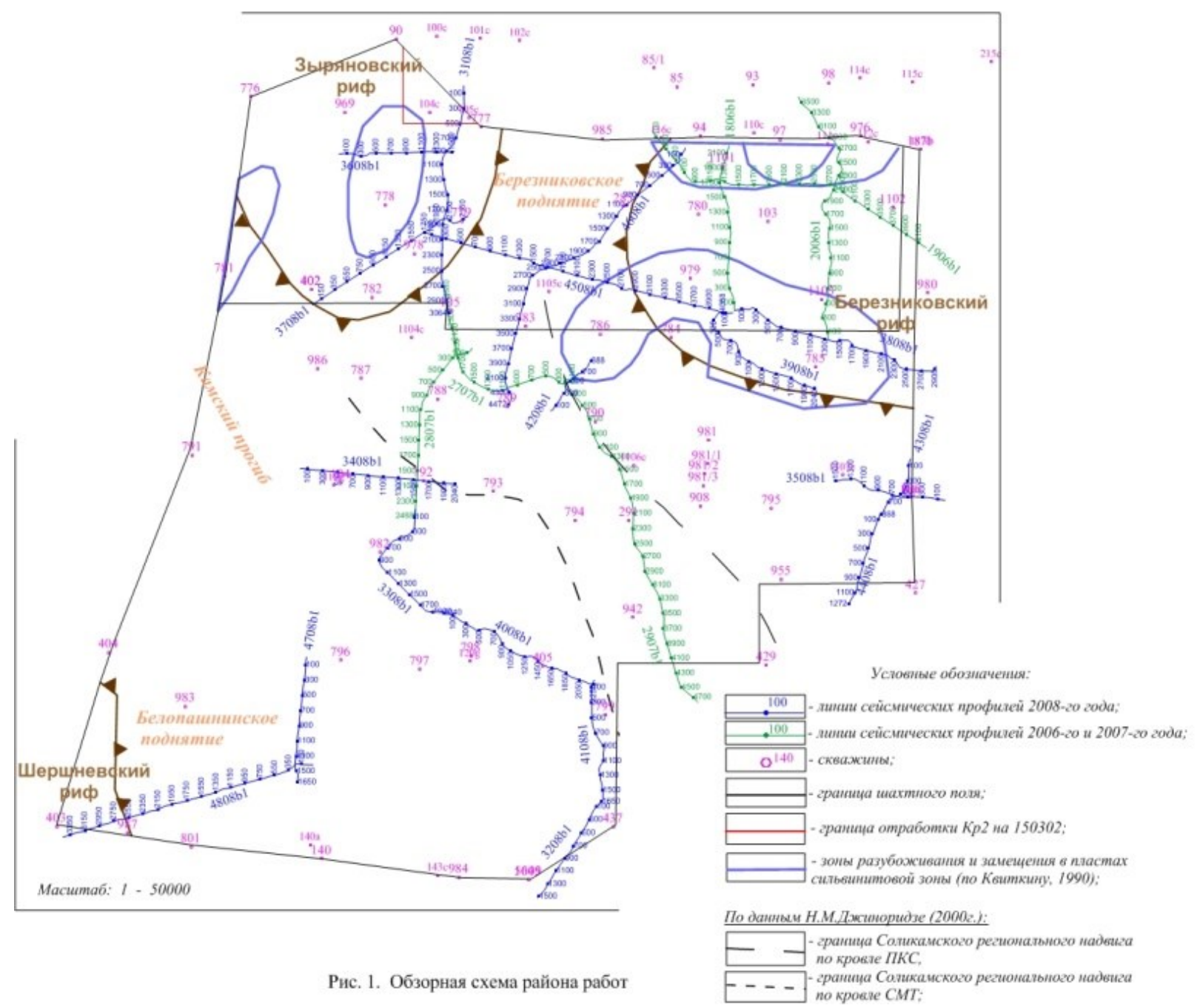

Рис. 1. Обзорная схема работ

В результате анализа рассчитанных как интегральных, так и дифференциальных спектральных характеристик на всех профилях, выполненных в разные годы, расположенных на больших расстояниях друг от друга, на участке работ определенно устанавливается, что превалирующая, доминантная, имеющая наибольший энергетический вклад в спектре сейсмической записи, видимая частота находится в полосе 75-80 ГЦ (рис. 2). Поведение доминантной частоты сейсмического сигнала примем за нормальное поле. Тогда, в процессе спектрального анализа первая задача состоит, прежде всего, в выявлении отклонений значений амплитуды спектральных составляющих от нормального поля, т.е. областей аномалий, оцениваемых по критерию параметра контрастности, определяемого как отношение приращения значений данного параметра от фоновых значений к погрешности определения фона, которая, в свою очередь, оценивает уровень помех.

Анализ поведения спектральных составляющих показал следующее. Обращают на себя внимание зоны, области «потери» энергии определенной гармоники, или, на сей- 
смическом сленге - «выпадения» данной гармоники из спектра. Так, на рисунке 2 наблюдаются такое «выпадение» гармоники с доминантной частотой 77 Гц на локальном участке в правой части профиля. В центре профиля, на локальном участке напротив - наблюдается увеличение энергии гармоник с более высокими, чем доминантная, частотами. Попытки установления связей аномалий спектральных характеристик с особенностями геологического строения среды возможны в первом приближении, исходя из принятия той или иной теории, гипотезы механизмов таких физических явлений как рассеяние и дифракция. Однако, на данном этапе осмысления результатов экспериментальных наблюдений, не вдаваясь в теоретические гипотезы о рассеянии и дифракции, следует отметить следующее. Оказалось очевидной пространственная приуроченность высокочастотной аномалии в центре профиля к выявленной нами предыдущими исследованиями (Semerikova, 2018) зоне развития мелких разноориентированных трещин, расположенной ниже отражающего горизонта МГ, приуроченного к тонкому прослою маркирующей глины. Увеличение же частотной координаты центроида в более ранних исследованиях нами установлено как поисковый признак трещиноватых зон такого класса [3].

В пределах участка аномалии пониженной интенсивности доминантной частотной составляющей спектра развиты низкоскоростная зона в надсоляных породах и высокоскоростная зона в карналлит-сильвинитовой зоне - в «зоне замещения карналлитовых и сильвинитовых солей каменной солью». И этот факт ассоциируется с понятием физического явления - «упругое рассеяние». Здесь же по данным структурных построений сейсморазведки - синклинальная форма в надсоляных породах.

Потрассные амплитудночастотные спекты
Суммарные амплитудночастотные спекты

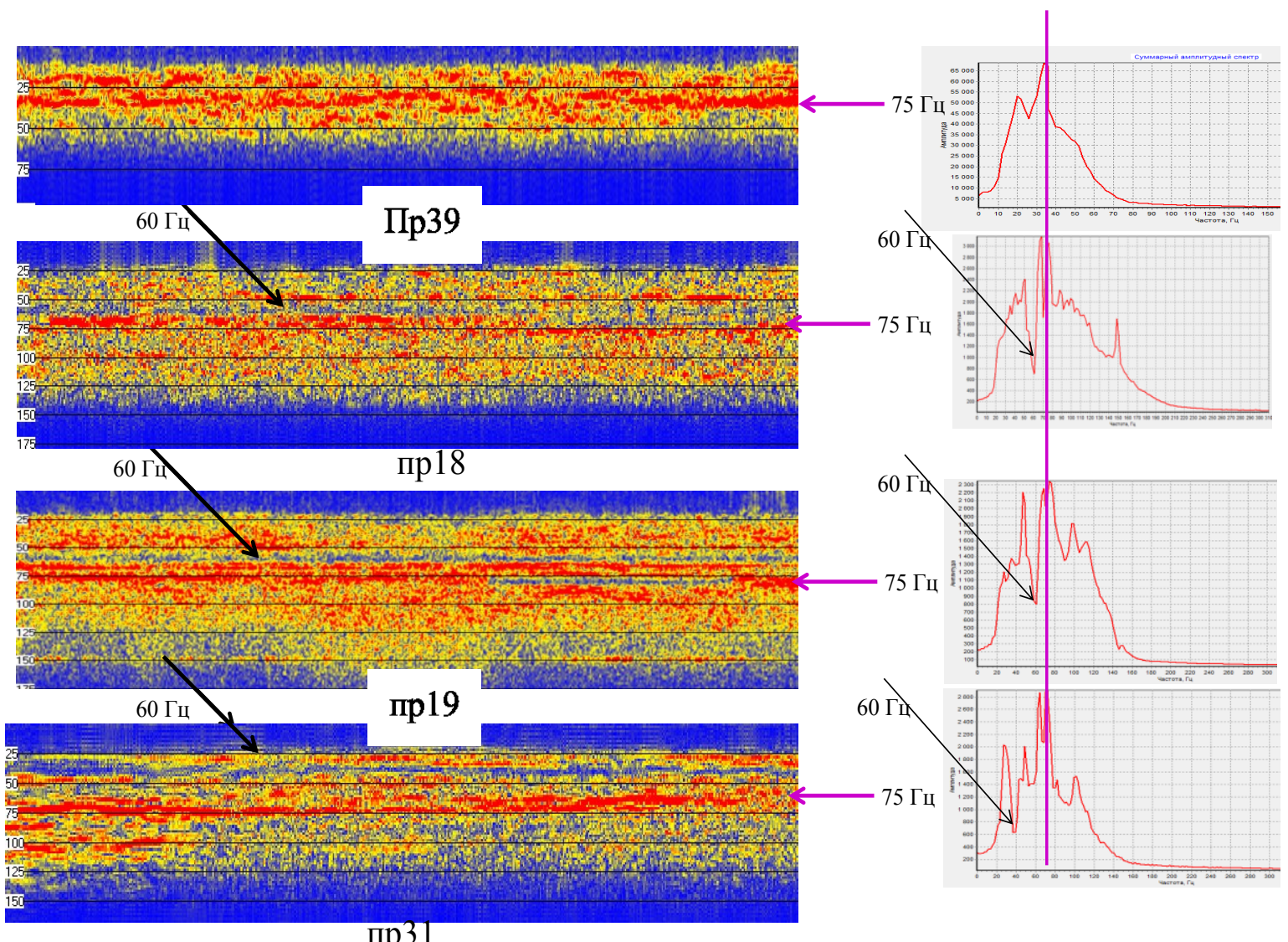

пр31

Рис. 2 . Потрассные и суммарные спектры для различных профилей 
На другом профиле, локальная по латерали аномалия потери энергии отмечается для гармоники с частотой 100 Гц. При совмещении с ситуационным планом шахтного поля в 300 м от профиля выполнена вертикальная горная выработка - «клетевой ствол» (рис. 2).
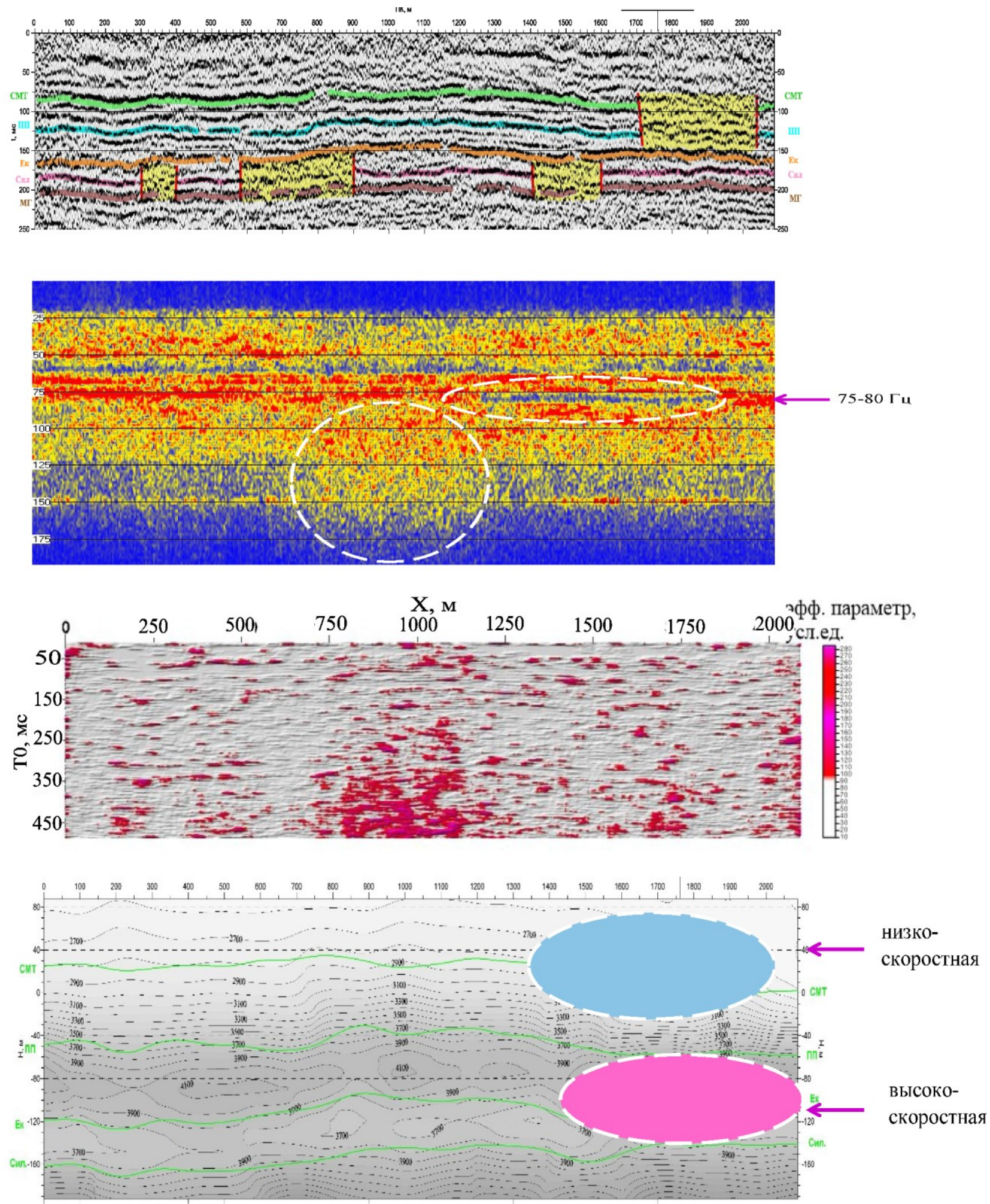

Рис. 3. Пространственное сопоставление временного разреза, потрассного амплитудного спектра, эффективного параметра вероятности наличия зоны мелкой разноориентированной трещиноватости и скоростного разреза 
Диаметр ствола определен исходя из обеспечения подачи в рудник расчетного количества воздуха для проветривания рудника и составляет 8 м в свету. Глубина стволов определена с учетом размещения подводящих выработок ниже слоя маркирующей глины, «ствол» является сложнейшим горнотехническим техногенным объектом, определяющим техногенную составляющую напряженно-деформированного состояния и изменяющую естественное поле напряжений. Этот объект можно представить локальной неоднородностью в геологическом разрезе. Тогда стенка ствола является самой акустически контрастной границей в массиве горных пород, ее можно аппроксимировать «свободной поверхностью», а сам объект «ствол» как разрывное нарушение малых латеральных размеров. Общепринято, что вертикальная разрешенность составляет 1/4 длины волны, которая в нашем случае (при скоростях распространения сейсмических волн $\mathrm{V}=2500-3500$ м/с и доминантной частоте $\mathrm{f}=75-80$ Гц, составляет 31 - 47 м) составляет 8-12 м. Горизонтальная разрешенность, определяемая как 1/6 диаметра первой зоны Френеля ( $R_{\Phi} \cong \sqrt{\lambda H / 2} \cong a \sqrt{\lambda H}$, ), которая в нашем случае на глубине 400 м составляет 158-193 м, соответственно составляет 26-32 м. Тогда, диаметр выработки меньше диаметра первой зоны Френеля в 17-22 раза и длины волны в 5-6 раз. Именно поэтому, мы не наблюдаем отклик от этого объекта на временном разрезе. Однако, как видим, он отображается в спектральных характеристиках.

Дополнительным доказательством может явиться то обстоятельство, что данная частотная аномалия в интервале до подстилающей соли проявляется, а ниже она не наблюдается.

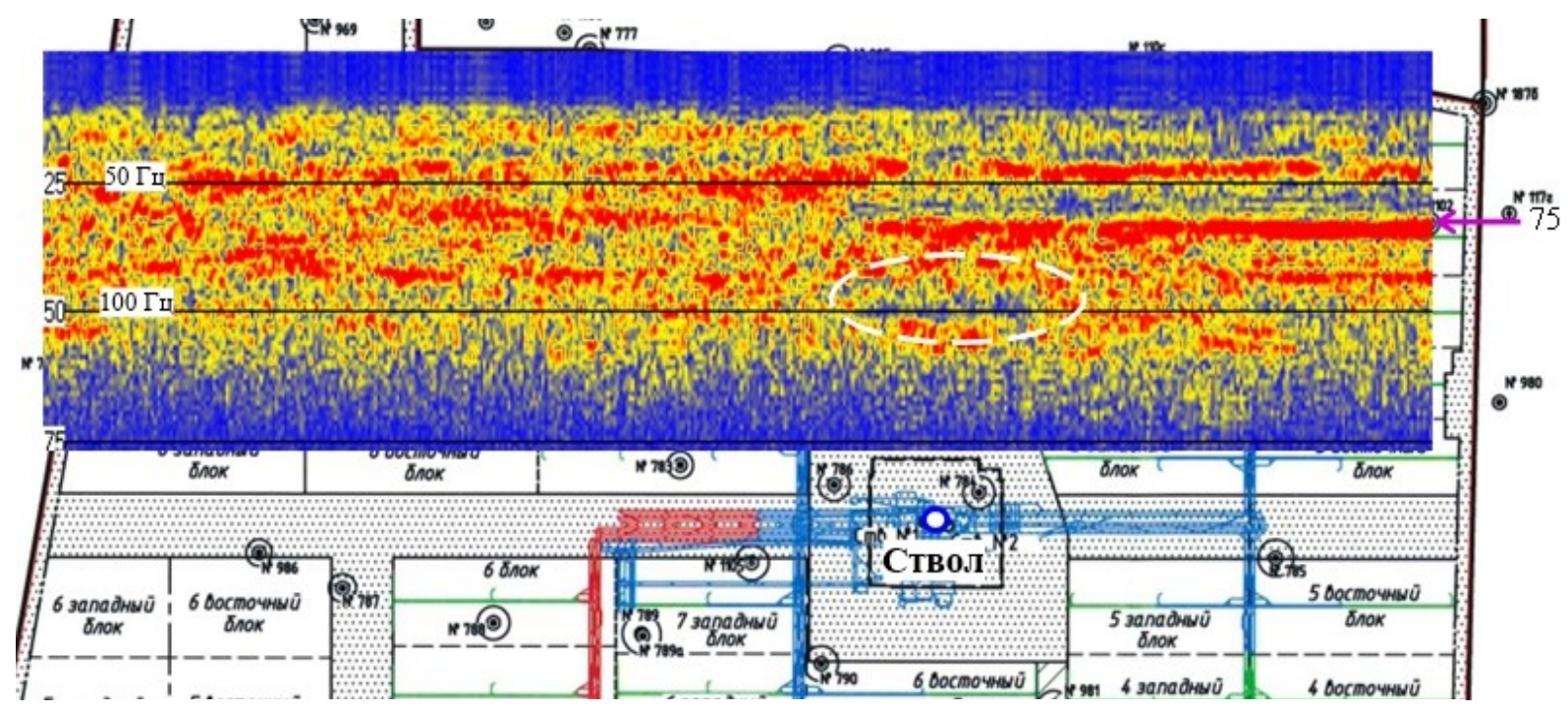

Рис. 4. Совмещение потрассного амплитудного спектра вдоль профиля и ситуационного плана шахтного поля

Справедливости ради, следует, сказать, что диаметр ствола в свету - 8 м, не является единственным фактором влияния на волновую картину. Конструкция ствола выработки такова, что по периметру осуществляется еще ряд кольцевых зон из дюбелей и замораживающих скважин, необходимых при проходке ствола для предотвращения прорыва грунтовых вод. Кроме того, сооружение любой горной выработки сопровождается нарушением естественного поля напряжений, внесением техногенных изменений в напряженно-деформированное состояние. Вокруг любой горной выработки образуется зона её влияния, теоретически размером примерно в 5 диаметров самой выработки, а в реальных условиях может быть другой размер. 
Эта зона состоит из кольцевых зон концентрации напряжений и зон разгрузки напряжений, вплоть до образования зон трещиноватости. Во всех этих зонах меняются петрофизические свойства и, в том числе, упругие характеристики горных пород. Таким образом, линейные размеры такой техногенной неоднородности, типа «ствол», увеличиваются по сравнению с диаметром ствола в свету. Это обстоятельство требует более детальных исследований изменения динамических характеристик упругих волн.

\title{
Выводы
}

Таким образом, выделяются локальные области уменьшения энергии доминантной частоты при наличии в разрезе скоростных неоднородностей. Выделяются локальные области повышенной энергии высокочастотных составляющих спектра сейсмического сигнала при наличии в разрезе зоны мелких разноориентированных трещин. На разрезах амплитудного спектра локальные области существенного уменьшения энергии высоких частот при наличии в разрезе вертикальной горной выработки типа «ствол». Диаметр выработки меньше диаметра первой зоны Френеля в 17-23 раза и длины волны в 5-6 раз. Отклик этого объекта не наблюдается на временном разрезе, но наблюдается в спектральных характеристиках.

\section{БИБЛИОГРАФИЧЕСКИЙ СПИСОК}

1. Кондратьев О.К. Разрешающая способность сейсморазведки МОВ-ОГТ // Геофизика. - 2006. - № 2. - С. 3-12.

2. Спасский Б.А., Герасимова И.Ю. Сейсмостратиграфия: учеб.-метод. пособие. - Пермь: Изд-во ПГУ, 2007. - 245 с.: ил.

3. Semerikova I.I. Studying of wave processes in a rock mass by technique for recognizing fractured zones in fields of seismic waves // Geomodel $2017-19^{\text {th }}$ Science and Applied Research Conference on Oil and Gas Geological Exploration and Development. - Gelendzhik, 2017. - код 135105 - DOI: 10.3997/22144609.201702274.

\section{МЕЖСКВАЖИННЫЕ СЕЙСМИЧЕСКИЕ ИССЛЕДОВАНИЯ ПРИ ИЗУЧЕНИИ ВОДОЗАЩИТНОЙ ТОЛЩИ НА АВАРИЙНОМ УЧАСТКЕ ВЕРХНЕКАМСКОГО МЕСТОРОЖДЕНИЯ КАЛИЙНЫХ СОЛЕЙ}

\author{
А.В. ЧУГАЕВ \\ Горный институт УрО РАН, г. Пермь
}

\begin{abstract}
Аннотация: Скважинные сейсмические исследования, проведенные на аварийном участке рудника СКРУ-2 Верхнекамского месторождения калийных солей позволяют расширить представление о состоянии изучаемого массива за счет увеличения частоты сейсмического сигнала и, соответственно, разрешающей способности, по сравнению с наземными сейсморазведочными методиками.

Даны методические рекомендации по параметрам систем расстановки и границам применения межскважинного сейсмического просвечивания на данном объекте. Сделан ряд интерпретационных заключений, которые согласуются с результатами наземных сейсмических исследований.

Ключевые слова: сейсмическое межскважинное просвечивание, скважинная сейсморазведка, сейсмотомография, Верхнекамское месторождение, амплитудная томография.
\end{abstract}

Изучение аварийного участка СКРУ-2 ведется с 1995 года, когда произошло разрушение междукамерных целиков на обширной территории, что привело к оседанию вышележащей толщи. С этого момента велся ежегодный мониторинг с помощью назем- 